Jurnal Interpretasi Hukum |ISSN: 2746-5047

Vol. 2, No. 2 - Agustus 2021, Hal.358-365| Tersedia online di https://www.ejournal.warmadewa.ac.id/index.php/juinhum

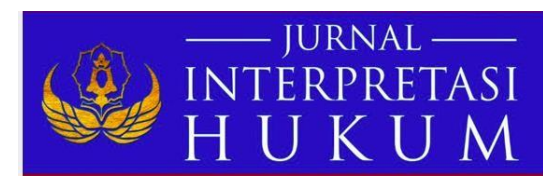

\title{
PERTANGGUNGJAWABAN LEMBAGA PERKREDITAN DESA (LPD) DESA ADAT UNGASAN ATAS KETIDAKMAMPUANNYA DALAM MEMENUHI HAK NASABAH PEMEGANG SIMPANAN
}

\author{
I Gede Surya Pratama Putra Dr. I Nyoman Sukandia \& Ni Made Puspasutari Ujianti \\ Fakultas Hukum Universitas Warmadewa, Denpasar-Bali, Indonesia \\ spratamaa9@gmail.com, nyomansukandia@gmail.com, puspa.niwapong@gmail.com
}

\begin{abstract}
Abstrak
LPD merupakan lembaga perekonomian milik Desa Adat. LPD dibentuk, dikelola oleh Desa pakraman, dan melayani transaksi keuangan hanya dalam lingkungan internal Desa pakraman. Pengurus LPD dipilih, ditetapkan, disahkan, dan diberhentikan melalui paruman Desa. Dari semua tingkatan pengurus LPD bersumber dari masyarakat adat dan tidak dapat menghindarkan masalah masalah yang timbul di dalam Lembaga, oleh karenanya penelitian ini berfokus untuk mengkaji bentuk pengelolaan pinjaman (kredit) terhadap nasabah sehingga menghindarkan terjadinya kredit macet di LPD Adat Ungasan, dan menelaah pertanggungjawaban LPD Adat Ungasan dalam memenuhi hak nasabah pemegang simpanan. Metode penelitian yang digunakan dalam penelitian ini adalah meode penelitian empiris dengan menggunakan pendekatan Berdasarkan hasil penelitian maka dapat disimpulkan bahwa prosedur pemberian kredit pada LPD ada empat bagian-bagian yang terlibat didalamnya yakni: bagian kredit, ketua LPD, bagian kasir dan bagian tata buku. Kemudian seluruh kerugian LPD desa adat ungasan ditanggung oleh desa adat, dalam hal desa adat sanggup memback up kerugian LPD Adat Ungasan, dengan syarat para pengurus LPD adat ungasan yang lama mengansur seluruh kerugian kepada desa adat karena desa adat adalah organisasi adat yang bersifat komunal atau mengedepankan kebersamaan.
\end{abstract}

Kata kunci: LPD, Prosedur Pemberian Kredit, Pertanggungjawaban Lembaga

\begin{abstract}
LPD is an economic institution belonging to the Traditional Village. LPD is formed, managed by Desa Pakraman, and serves financial transactions only within the internal environment of Desa Pakraman. LPD administrators are elected, stipulated, legalized, and dismissed by means of the village paruman. From all levels the LPD management comes from indigenous peoples and cannot avoid problems that arise in the institution, thus, this research focuses on to manage loans (credit) to customers so as to avoid bad credit at the Village Credit Institution (LPD) Adat Ungasan and to examine the responsibility of the Ungasan Traditional Village Credit Institution (LPD) in fulfilling the rights of customers who hold deposits. The research method used in this research is empirical research method. Based on the research results, it can be concluded that there are four parts to the procedure for giving credit to the LPD, namely: The Credit Section, the Head of the LPD, the Cashier Section and the Bookkeeping Section. Furthermore, all losses of the Ungasan Traditional Village LPD shall be borne by the Traditional Village, in the event that the Traditional Village is able to back up the losses of the Ungasan Customary $L P D$, provided that the old Ungasan LPD administrators cover all losses to the Traditional Village because the Traditional Village is a communal customary organization or promoting togetherness.

Keywords: LPD, Credit Granting Procedures, Institutional Responsibility
\end{abstract}

\section{PENDAHULUAN}

LPD merupakan lembaga perekonomian milik Desa pakraman. LPD dibentuk oleh Desa pakraman, Dikelola oleh Desa pakraman, dan melayani transaksi keuangan hanya dalam lingkungan internal Desa pakraman. LPD dibentuk melalui rapat desa (Paruman Desa). Pengurus LPD dipilih, ditetapkan, disahkan, dan diberhentikan melalui rapat desa (Paruman Desa). Lembaga Perkreditan Desa dikelola melalui perarem, semacam anggaran dasar dan 
anggaran rumah tangga yang di tetapkan melalui rapat desa (Paruman Desa). Berdasarkan proses pembentukan sifat khas bentuknya, dan pengelolaan secara otonom oleh Peraturan daerah Provinsi Bali diberikan kepada Desa pakraman, maka LPD pada hakekatnya merupakan lembaga adat yang mengemban fungsi ekonomi keuangan pada desa pakraman. LPD merupakan Lembaga Keuangan Komunitas (LKK), lembaga adat, dan bukan lembaga keuangan umum, baik dari segi visi, misi, kepemilikan, permodalaan, pengelolaan, sifat layanan transaksi keuangan yang diselenggarakan, dan tujuannya (I Nyoman Sukandia, Lembaga Perkreditan Desa, 2019). Dalam mencapai tujuannya, LPD tidak semata menggunakan modal sosial dalam struktur pengendaliannya (Gunawan, 2010)

LPD yang tersebar di wilayah Bali merupakan bisnis jasa keuangan yang dikelola oleh Desa Pekraman atau Desa Adat. Badan usaha LPD sepenuhnya dimiliki dan dikelola oleh Desa Adat, merupakan lembaga bisnis yang dikelola dengan tujuan untuk memperoleh laba (Sukandia, 2019). Segala yang dibendakan LPD Adat ungasan memakai system tanggungjawab tanggung renteng yang artinya menanggung segala beban bersama sama (Sukandia, 2019). Arti Pertanggungjawaban, Pertanggungjawaban memiliki 2 arti. Pertanggungjawaban berasal dari kata dasar tanggung jawab. Pertanggungjawaban adalah sebuah homonim karena arti-artinya memiliki ejaan dan pelafalan yang sama tetapi maknanya berbeda. Segala yang dibendakan LPD Adat ungasan memakai system tanggungjawab tanggung renteng yang artinya menanggung segala beban bersama sama.

LPD yang berbasis masyarakat hukum adat di desa pakraman yang beroperasi untuk menggerakan perekonomian pedesaan dalam bentuk perkreditan rakyat, tetapi juga mempunyai misi untuk melestarikan adat istiadat dan tradisi serta menjaga keajegan budaya masyarakat bali yang dijiwai ajaran Hindeu yang disebut Tri Hita Karana, yaitu tiga sumber kebahagiaan dalam dimensi hubungan yang serasi dan selaras serta harmoni antara manusia kepada sang pencipta Tuhan Yang Maha Esa, antara manusia dengan sesama manusia, dan hubungan serasi antara manusia dengan alam semesta. Karena itu, kehidupan masyarakat hukum adat dalam desa pakraman di bali selalu berorientasi pada kehidupan dunia nyata (skala) dan dunia spriritualmagis-religius (niskala) yang tercermin dalam wujud hukum adat yang tertulis (awig-awig) sebagai dasar pendirian LPD di Bali. Keberadaan dan kinerja LPD di Bali harus diatur dan diberlakukan secara khusus karena berbeda dengan Lembaga keuangan yang berbasis masyarakat hukum adat di luar Bali, LPD di Bali didirikan berdasarkan hukum adat oleh, dari, dan untuk karma desa berbasis masyarakat hukum adat.

Kredit adalah instrumen keuangan yang memungkinkan individu atau badan usaha meminjam uang untuk membeli produk dan mengembalikan produk dalam waktu tertentu. Jika seseorang menggunakan jasa kredit, ia akan dikenakan bunga atas tagihan tersebut. Pengertian kredit adalah kemampuan untuk melakukan pembelian atau menjanjikan pinjaman yang akan dibayarkan dalam jangka waktu yang disepakati. Astiko (1996). Kredit yang diberikan dalam LPD di Ungasan tanpa melalui prosedur yang sulit dan yang selama ini bukan menjadi kendala bagi masyarakat golongan ekonomi lemah (Naja, 2005).

Pemberian kredit oleh LPD Ungasan ini tidak selalu berjalan lancar dan baik sesuai yang diharapkan, walaupun di pemberian kredit sudah terjadinya perjanjian, karena bisa saja terjadi kendala dalam pelaksanaan kredit, yang dimana suatu saat pihak kreditur dapat mengalami kesulitan untuk meminta angsuran dari pihak debitur karena Dalam beberapa hal, kendala yang dihadapi adalah kredit macet. Adanya credit line memberikan kemudahan bagi konsumen yang menggunakannya. Secara fisik, mereka bahkan bisa menikmatinya sebelum melunasi barangnya. Selain itu, pembayaran dapat dilakukan secara kredit tanpa menambah beban keuangan. Namun banyak orang yang menggunakan fitur ini untuk berpose di depan umum, dan beberapa konsumen tidak mampu membayar karena gaji bulan itu belum dibayarkan. Pada saat pengajuan kredit di LPD Desa Ungasan juga ditandatangani perjanjian penjaminan antar pemohon kredit. Jaminan adalah sesuatu yang diberikan debitur kepada kreditur, sehingga kreditor yakin bahwa debitur akan melunasi utang sesuai dengan kesepakatan, karena jaminan berfungsi untuk memprediksi apakah suatu masalah akan terjadi. Permasalahan yang terjadi pada Lembaga Perkreditan Rakyat (LPD) Desa Ungasan adalah 
debitur lalai dalam memenuhi kewajibannya untuk mengembalikan kredit dan telah memberikan jaminan hak tanggungan kepada debitur. Perilaku debitur tersebut mengakibatkan kredit macet, sehingga terjadi perlu tinggal di Desa Ungasan Selesaikan bila terjadi kredit macet di lembaga kredit (LPD).

Dengan adanya permasalahan di Lembaga Perkreditan Desa (LPD) Desa adat Ungasan yang disebabkan oleh lalainya ketua LPD dan Kabag Kredit LPD Desa adat Ungasan mengambil keputusan. Hal ini terjadi pada kasus peminjaman dana oleh nasabah LPD Desa Ungasan berjumlah 50.000.000.000 dengan menjaminkan tanah seluas $1 \mathrm{Ha}$ dan mobil taxi berjumlah 75 Unit yang berada diluar wilayah Desa Ungasan. Beberapa tahun kemudian nasabah yang meminjam dana tersebut tidak bisa mengansur pembayaran, sehingga jaminan yang di jaminkan di ambil alih pihak LPD dan dana mengendap berupa barang jaminan.

Pada suatu ketika ada nasabah yang ingin mengambil dana dari tabungan pihak LPD Desa Ungasan tidak bisa mencairkan dana karena dana yang di miliki oleh Lembaga Perkreditan Desa masih mengendap berupa barang. Lambat laun berita ini semakin menyebar luas di kalangan masyarakat Desa Ungasan, hal ini disebabkan oleh kurangnya komunikasi antara pihak internal dan salah mengambil kebijakan oleh ketua LPD yang Lama. Sehingga para nasabah yang menaruh dana tidak terima dengan hal ini dan masyarakat pun mendesak untuk memproses ke meja hijau. Kasus yang terjadi di LPD Ungasan merupakan kerugian terhadap nasabah yang menempatkan dana pada LPD Ungasan.

Beberapa penelitian terdahulu yang relevan dengan penelitian ini. Atmadja et al (2015) mengkaji tentang pengaruh implementasi good corporate governance dan proteksi awig-awig terhadap kinerja lembaga perkreditan desa (LPD) dengan budaya menyama braya sebagai variabel moderasi. Penelitian selanjutnya menghubungkan budaya Tri Hita Karana dengan prisip good governance dalam kinerja manajerial Lembaga Pengkreditan Desa (LPD) di Desa Pakraman Padangsambian (Yandani \& Suryanata, 2019). Selanjutnya, ada penelitian yang menelaah mengenai kebangkrutan yang dialami oleh LPD di Kabupaten Buleleng-Bali karena beberapa faktor yaitu faktor perlindungan hukum, kompensasi manajerial, good corporate governance, peran aktif dari warga negara dan peran badan-badan pengawas internal (Saputra et al., 2019).

Dari semua tingkatan pengurus LPD bersumber dari masyarakat adat dan tidak dapat menghindarkan masalah masalah yang timbul di dalam Lembaga, oleh karenanya penelitian ini berfokus untuk mengkaji bentuk pengelolaan pinjaman (kredit) terhadap nasabah sehingga menghindarkan terjadinya kredit macet di LPD Adat Ungasan, dan menelaah pertanggungjawaban LPD Adat Ungasan dalam memenuhi hak nasabah pemegang simpanan.

\section{METODE PENELITIAN}

Metode penelitian yang digunakan dalam penulisan Jurnal ini adalah tipe penelitian hukum empiris. Metode ini dipakai untuk melihat fungsi hukum dimasyarakat (Marzuki, 2005). Sedangkan pendekatan masalah yang digunakan adalah pendekatan sosiologis. Pendekatan sosiologis adalah metode yang berlandaskan fenomena dimasyarakat yang menjadi objek dalam penelitian. Dalam memperoleh data pada penelitian ini peneliti menggunakan Teknik wawancara dan Teknik obersevasi langsung di lapangan. Dalam penggunaan Teknik wawancara dimaksudkan agar perolehan data dan keefektivan target wawancara dapat langsung dipastikan, sehingga wawancara tersebut tidak menyimpang dari yang direncanakan (Sunggono, 2016). Setelah data terkumpul, selanjutnya dianalisis secara kualitatif dekriptif. Penelitian ini berlokasi di Jalan Bali Cliff lingkungan Banjar kangin, Desa Ungasan, Kecamatan Kuta Selatan, Kabupaten Badung-Bali. Untuk mengkaji penelitian ini peneliti membutuhkan bahan hukum untuk menguatkan penelitiannya. Sumber bahan hukum primer penelitian ini berasal dari perundang-undangan, sedangkan bahan hukum sekunder penelitian ini berasal dari jurnal-jurnal hukum dan buku-buku hukum yang berkaitan dengan kasus dalam penelitian ini. 


\section{HASIL DAN PEMBAHASAN}

\section{Pengelolaan Pemberian Kredit Pada Lembaga Pekreditan Desa (LPD)}

Kata "kredit" berasal dari bahasa Latin, yang merupakan kombinasi dari Credo (artinya "Saya percaya") (Cred dalam bahasa Sansekerta berarti "kepercayaan") dan Latin Do (artinya "Saya tempat"). Mendapatkan kredit berarti mendapatkan kepercayaan. Atas dasar kepercayaan mereka yang membutuhkan, memberikan uang, barang atau jasa secara bersyarat untuk membayar kembali atau memberikan pengganti dalam waktu yang disepakati (Rahardjo, 1997). Beberapa lembaga keuangan telah banyak melakukan kegiatan komersial, salah satunya menyalurkan dana kepada masyarakat yang selanjutnya disebut pinjaman atau kredit. Tujuan Pemberian Kredit Tujuan pemberian kredit melalui lembaga keuangan dan program kemasyarakatan pada umumnya adalah untuk kesejahteraan masyarakat dan pembangunan ekonomi.

Sejak berdirinya LPD, keberadaan LPD sebagai badan usaha keuangan di Desa Pakraman telah didasarkan pada "Ketentuan Lembaga Perkreditan Desa di Provinsi Bali". Pemerintah Bali merumuskan "Peraturan Daerah" yang intinya mengakui, melindungi, menjaga, mendorong dan mendorong peningkatan kapasitas dan kemajuan LPD. Unsur kredit yang paling esensial adalah "Kepercayaan" bank/kreditur terhadap nasabah/debitur.

Prosedur pemberian kredit pada LPD desa ada empat bagian-bagian yang terlibat didalamnya yakni:

1. Bagian Kredit;

2. Ketua LPD;

3. Bagian Kasir;

4. Bagian Tata Buku.

Adapun Formulir-formulir yang digunakan dalam melakukan transaksi pemberian kredit adalah sebagai berikut:

1. Surat Permohonan Pinjaman;

2. Surat Perjanjian Kredit;

3. Bukti Penerimaan Kredit;

4. Bukti Kas Keluar;

5. Bukti Kas Masuk;

6. Bukti Penerimaan Jaminan;

7. Surat Pernyataan Penyerahan Jaminan.

Didalam mengeluarkan kredit untuk masyarakat harus menerapkan prinsip kehati-hatian Penerapan Prinsip Kehati-hatian pada Prosedur Penyaluran Kredit oleh LPD Pemberian kredit pada LPD memiliki pedoman dalam proses pemberian kredit yang mengacu pada pedoman LPD Bali. Menjaga hubungan baik dengan para debitur menjadi salah satu cara LPD dan hal tersebut menjadikan rasa nyaman bagi calon debitur dalam proses pengajuan kredit sampai dengan jangka waktu pelunasan. Inti dari proses pemberian kredit pada LPD adalah memperhatikan prinsip cepat, sederhana, dan kedekatan hubungan. Cepat artinya dengan mendatangi debitur (jemput bola), keputusan kredit dilakukan oleh manajemen LPD sehingga mempercepat proses kredit, dan pencairan cepat agar memenuhi tuntutan bisnis. Sederhana artinya adminsitrasi dan persyaratan mudah dipenuhi dengan pemutus kredit satu atap. Dan pemberian kredit yang diberikan diharapkan mampu meningkatkan usaha debitur. LPD harus selalu melakukan analisis 5C dan KYC (know your customer) seperti lembaga keuangan lainnya yaitu character (watak), capacity (kemampuan), capital (modal), collateral (jaminan), dan condition of economy (kondisi ekonomi), namun juga masih menerapkan sistem kekeluargaan dalam menyalurkan kredit kepada calon debitur.

\section{Pertanggungjawaban LPD terhadap Nasabah Pemegang Simpanan di Desa Adat Ungasan}

Lembaga perkreditan desa di desa adat Ungasan mengalami kesibukan pada tahun 2018. Nasabah berbondong-bondong menarik simpanannya dalam bentuk tabungan dan deposito. 
Desakan tersebut dipicu oleh masalah investasi keuangan LPD Ungasan yang diduga melanggar peraturan perundang-undangan yang aktif berupa peraturan daerah dan hukum adat setempat. Kemudian, kasus tersebut melibatkan tiga pihak, yakni Bendesa Adat Ungasan, Ketut Marcin, Ketua LPD Ungasan Ngurah Sumaryana, dan Pengamat Kredit Made Suka Arjana, yang juga Ketua Panitia Pengawas LPD Ungasan. Dilihat dari hasil audit, yang jelas lalai hanya Kepala BP, Ketua LPD dan Analis Perkreditan. Di saat yang sama, para eksekutif lainnya juga mengakui bahwa mereka cuek dan tidak pernah setuju untuk menggunakan agunan jauh di bawah nilai kredit untuk berinvestasi di kredit perumahan, tanah dan taksi.

"Nanti yang menentukan dia diberhentikan atau tidak adalah paruman desa. Yang sudah dilakukan adalah paruman kelian adat. Tetapi nanti kalau kelian adat tak mengambil keputusan yang bulat, maka akan sampai pada paruman desa. Paruman desa merupakan yang tertinggi. Paruman desa dapat memberhentikan siapa saja dan itu telah diatur dalam awig-awig Desa Adat Ungasan," ujar (Ketua Kertha Desa Ungasan I Nyoman Mindra, Kamis, 6 Juli 2018). Ketut Marcin sendiri pada akhirnya diberhentikan sebagai Bendesa Adat Ungasan. Hasil pemeriksaan lebih lanjut, LPD Ungasan diduga merugi puluhan miliar rupiah. Kerugian tersebut disebabkan oleh dugaan reputasi buruk dan kenaikan harga rumah di Lombok, Nusa Tenggara Barat.

Berdasarkan dari paparan diatas, dapat dikatakan bahwa kelemahan dalam analisa kredit, ini bisa disebabkan oleh berbagai hal diantaranya yaitu lemahnya kebijakan dan standar operasional prosedur dalam analisa kredit, salahnya mengambil kebijakan dalam mengeluarkan kredit, dan Terlalu luas, pengejaran pinjaman bank akan mengabaikan semua aspek analisis yang baik atau mengurangi kehati-hatian. Sejarah pelanggan adalah satu-satunya dasar untuk keputusan kredit, sehingga analisis kredit diabaikan. Lembaga Perkreditan Desa jangan hanya melihat agunan sebagai dasar keputusan pemberian kredit, sehingga faktor-faktor analisa yang lainnya terabaikan.

Tabel 1.1

Laporan Akhir Tahun LPD Desa Adat Ungasan, Kecamatan Kuta Selatan, Kabupaten Badung, Provinsi Bali, tahun 2018 s/d 2020

\begin{tabular}{|c|c|c|c|c|}
\hline \multirow{2}{*}{ No } & \multirow{2}{*}{ Indkator } & 2018 & 2019 & 2020 \\
\cline { 3 - 5 } & Penyimpan & 10.221 & 10.221 & 10.221 \\
\hline 2 & Peminjam & 623 & 819 & 744 \\
\hline
\end{tabular}

Sumber: LPD Desa Adat Ungasan, Kecamatan Kuta Selatan, Kabupaten Badung, Provinsi Bali, tahun 2018 s/d 2020

Table 1.2

Laporan Akhir Tahun LPD Desa Adat Ungasan, Kecamatan Kuta Selatan, Kabupaten Badung, Provinsi Bali, tahun 2018 s/d 2020

\begin{tabular}{|c|c|c|c|c|}
\hline \multirow{2}{*}{ No } & \multirow{2}{*}{ Peminjam } & 2018 & 2019 & 2020 \\
\cline { 3 - 5 } & Desa Adat & 620 & 818 & 743 \\
\hline 2 & Luar Desa Adat & 3 & 1 & 1 \\
\hline
\end{tabular}

Sumber: LPD Desa Adat Ungasan, Kecamatan Kuta Selatan, Kabupaten Badung, Provinsi Bali, tahun 2018 s/d 2020 
Table 1.3

Laporan Akhir Tahun LPD Desa Adat Ungasan, Kecamatan Kuta Selatan, Kabupaten Badung, Provinsi Bali, tahun 2018 s/d 2020

\begin{tabular}{|c|c|c|c|c|}
\hline \multirow{2}{*}{ No } & \multirow{2}{*}{ Kolektibilitas } & 2018 & 2019 & 2020 \\
\cline { 3 - 5 } & Lancar & 429 & 708 & 341 \\
\hline 2 & Kurang Lancar & 73 & 106 & 154 \\
\hline 3 & Macet & 83 & 3 & 153 \\
\hline 4 & Diragukan & 38 & 2 & 96 \\
\hline
\end{tabular}

Sumber: LPD Desa Adat Ungasan, Kecamatan Kuta Selatan, Kabupaten Badung, Provinsi Bali, tahun 2018 s/d 2020

Berdasarkan paparan data diatas yang telah ditampilkan melalui tabel, maka faktor yang mempengaruhi hak nasabah pemegang simpanan tidak dapat dipenuhi oleh LPD Desa Adat Ungasan adalah banyak terjadinya kredit macet pada tahun 2018. Hal inilah yang menyebabkan terjadinya hak yang tidak terpenuhi pemegang simpanan oleh LPD Desa Adat Ungasan. Mengingat dana yang disalurkan untuk kredit berasal dari masyarakat, kredit macet juga mengakibatkan LPD Desa Adat Ungasan kekurangan dana sehingga mempengaruhi kegiatan usaha LPD Desa Ungasan (Wawancara dengan Bapak I Wayan Disel Astawa, SE, sebagai Bendesa Adat Ungasan, 27 Desember 2020). Data diatas juga menjelaskan bahwa Faktor faktor penyebab terjadinya kredit macet di LPD Desa Adat Ungasan adalah peminjaman uang yang tidak bisa diangsur oleh nasabah dan hanya berupa barang jaminan, maka dari inilah yang menyebabkan LPD Desa Adat Ungasan mengalami Rush pada tahun 2018. Adapun cara untuk menyelesaikan kredit macet, secara umum ada cara untuk menyelesaikan kredit macet yang harus dilakukan oleh pihak LPD Desa adat ungasan dengan menggunakan $6 \mathrm{C}$ yaitu:

a. Character (kepribadian / Watak)

b. Capacity (kemampuan)

c. Capital (modal)

d. Collateral (jaminan)

e. Condition of Economic (kondisi ekonomi)

f. Constrain (batasan atau hambatan)

Bentuk Pertanggung jawaban Lembaga Perkreditan Desa Mengenai pengelolaan keuangan Desa Pakraman telah diatur dalam Peraturan Daerah Kabupaten No 90 Provinsi Bali. 3 Maret 2017, tentang perubahan Peraturan Daerah Provinsi Bali Nomor 34 April 2012 dan Pasal 18, dalam rangka memperkuat, melindungi dan melindungi hak-hak karakteristik Desa Pakraman, termasuk mengelola potensi keuangannya dengan Desa Pakraman. hak-hak lain terkait kemandirian negara, Pemerintah Provinsi Bali juga telah menerbitkan "Peraturan Daerah Provinsi Nomor 3 Tahun 2017" Bali, yang melibatkan lembaga perkreditan desa dan pada prinsipnya bertujuan untuk mengisi kekosongan hukum terkait fungsi pengelolaan keuangan desa. LPD merupakan salah satu komponen penyelenggara Desa Pakraman yang menjalankan fungsi keuangan Desa Pakraman untuk mengelola potensi keuangan Desa Pakraman.

Kerugian yang dialami LPD Desa Adat Ungasan memiliki dua opsi pertanggung jawaban yaitu, pertama ditanggung oleh Desa Adat jika pengelola atau pengurus yang menimbulkan kerugian belum mampu mengganti kerugian yang ditimbulkan dengan jangka waktu yang cepat, yang kedua dengan opsi dimana Bendesa Adat Ungasan yang baru terpilih memberikan suntikan dana kepada LPD Desa Adat Ungasan untuk dikelola kembali kepada masyarakat Desa Adat (Wawancara dengan Bapak I Wayan Disel Astawa, SE, sebagai Bendesa Adat Ungasan, 27 Desember 2020). Sehingga kerugian yang dialami oleh nasabah penyimpan 
yang uangnya hilang di LPD Desa Adat Ungasan, juga mendapatkan pertanggungjawab oleh pihak LPD Desa Ungasan. Dalam hal ini Desa Adat dan Bendesa Adat sanggup memback up kerugian LPD Adat Ungasan, dengan syarat para pengurus LPD Adat ungasan yang lama mengansur seluruh kerugian kepeda Desa Adat karena Desa Adat adalah organisasi adat yang bersifat komunal atau mengedepankan kebersamaan.

\section{KESIMPULAN DAN SARAN}

\section{Kesimpulan}

Berdasarkan uraian pembahasan diatas, maka dapat disimpulkan bahwa dalam posedur pemberian kredit pada LPD desa ada empat bagian-bagian yang terlibat didalamnya seperti, bagian kredit, ketua LPD, bagian kasir, dan bagian tata buku. Dalam pengajuan kredit, kreditur juga wajib menyediakan berkas yang telah ditentukan oleh pihak LPD sebagai kelengkapan administrasi.

Kerugian yang dialami LPD Desa Adat Ungasan memiliki dua opsi pertanggung jawaban yaitu, pertama ditanggung oleh Desa Adat jika pengelola atau pengurus yang menimbulkan kerugian belum mampu mengganti kerugian yang ditimbulkan dengan jangka waktu yang cepat, yang kedua dengan opsi dimana Bendesa Adat Ungasan yang baru terpilih memberikan suntikan dana kepada LPD Desa Adat Ungasan untuk dikelola kembali kepada masyarakat Desa Adat Sehingga kerugian yang dialami oleh nasabah penyimpan yang uangnya hilang di LPD Desa Adat Ungasan, juga mendapatkan pertanggungjawab oleh pihak LPD Desa Ungasan. Dalam hal ini Desa Adat dan Bendesa Adat sanggup memback up kerugian LPD Adat Ungasan, dengan syarat para pengurus LPD Adat ungasan yang lama mengansur seluruh kerugian kepeda Desa Adat karena Desa Adat adalah organisasi adat yang bersifat komunal atau mengedepankan kebersamaan.

\section{Saran}

Pada kesempatan ini peneliti ingin menyampaikan beberapa saran yang diharapkan dapat menjadi bahan pertimbangan dalam mengambil keputusan untuk LPD kedepannya dan agar dapat menjadikan LPD lebih maju lagi. Pertama, peneliti mengharapkan agar setiap mengeluarkan kredit kepada masyarakat dengan jumlah lebih dari sepuluh milyar pihak LPD harus melaksakan sebuah rapat interen dengan pihak lembaga dan Bendesa Adat karena Lembaga Perkreditan Desa merupakan dibawah naungan Desa Adat. Seluruh kegiatan yang dilakukan oleh LPD harus menggunakan prinsip kehati-hatian agar meminimalisir kesalahan yang terjadi.

\section{DAFTAR PUSTAKA}

Astiko. (1996). Pengantar Manajemen Perkreditan. Andi Offset, Yogyakarta.

Atmadja, A. T., Darmawan, N. A. S., \& Saputra, K. A. K. (2015). Pengaruh Implementasi Good Corporate Governance Dan Proteksi Awig-Awig terhadap Kinerja Lembaga Perkreditan Desa (LPD) dengan Budaya Menyama Braya Sebagai Variabel Moderasi. Prosiding Konferensi Regional Akuntansi II.

Gunawan, K. (2010). Analisis Faktor Kinerja Organisasi Lembaga Perkreditan Desa di Bali (Suatu Pendekatan Perspektif Balanced Scorecard). Institute of Research and Community Outreach - Petra Christian University.

Marzuki, P. M. (2005). Penelitian Hukum. Kencana Pranada Media Group.

Naja, H. R. D. (2005). Hukum kredit dan bank garansi. Citra Aditya Bakti, Jakarta.

Rahardjo, P. (1997). Ekonomi: Kurikulum 1994 (Cet.2). Indah Pariwara, Klaten.

Saputra, K. A. K., Trisnadewi, A. A. A. E., Anggiriawan, P. B., \& Kawisana, P. G. W. P. (2019). Kebangkrutan Lembaga Perkreditan Desa (LPD) Berdasarkan Analisis Berbagai Faktor. Jurnal Ilmiah Akuntansi, Vol.4(1).

Sukandia, I. N. (2019). Lembaga perkreditan desa: berbasis masyarakat hukum adat di Bali. Nuswantara, Bali.

Sunggono, B. (2016). Metodologi penelitian hukum (Cetakan Ke). PT RajaGrafindo Persada, Jakarta. 
Jurnal Interpretasi Hukum Vol. 2, No. 2, 2021

Yandani, N. M. M., \& Suryanata, I. G. N. P. (2019). Padangsambian, Pengaruh Penerapan Prinsip-Prinsip Good Corporate Governance Dan Budaya Tri Hita Karana Terhadap Kinerja Manajerial Lembaga Perkreditan Desa (LPD) Pakraman. Jurnal Ilmiah Akuntansi Dan Bisnis, Vol.4(1). 